\title{
Under glass weathering of hemp fibers reinforced polypropylene biocomposites: Impact of Volatile Organic Compounds emissions on indoor air quality
}

\author{
Célia Badji, Joana Beigbeder, Hélène Garay, Anne Bergeret, Jean-Charles Bénézet, \\ Valérie Desauziers*
}

C2MA, Ecole des Mines d'Alès, 6 Avenue de Clavières, 30319, Alès Cedex, France

\begin{abstract}
A B S T R A C T
Nowadays, natural fibers reinforced composite materials can be used in closed environments such as car cabins. It has hence become a necessity to study their emissions of Volatile Organic Compounds (VOCs) to check their impact on indoor air quality. The purpose of this work was first to study the emissions of VOCs from hemp fibers reinforced polypropylene (PP) biocomposites in comparison with neat PP. The influence of under windshield glass weathering on VOCs release was then investigated. The exposition lasted one year and the fiber loading influence on emissions was studied all along the weathering. The VOCs concentration at the material/air interface was determined using a passive sampling method involving an emission cell coupled with Solid Phase MicroExtraction (SPME). VOCs analysis was then carried out by gas chromatography coupled to mass spectrometry and flame ionization detections. One of the most significant results is the drastic increase of oxygenated compounds concentration during the exposition, especially for biocomposites. Among these oxidation by-products, formaldehyde, acetaldehyde, furfural and 2-furanmethanol, recognized as Cancerogen, Mutagen and toxic for Reproduction (CMR), were detected. A broad range of alkanes, specific of PP matrix degradation was also identified. Finally, measured concentrations of substances found in this work and listed in Vehicle Indoor Air Quality (VIAQ) standards were gathered in order to discuss the biocomposites emissions impact on indoor air quality.
\end{abstract}

Keywords:

Vegetal fibers

Polypropylene

Weathering

Volatile Organic Compounds emission

Car cabin indoor air

\section{Introduction}

The development of natural fibers used as an alternative to glass fibers in the reinforcement of thermoplastic polymers has grown as the result of environmental concerns and the depletion of fossil resources. Indeed, their low density, good specific properties and low environmental impact make them attractive in fields like automobile and construction (decking). Moreover, the production of natural fibers composites could increase from 92,000 metric tons (MT) in 2012 to $370,000 \mathrm{MT}$ in 2020 according to the incentives [1].

Concerning automotive sector, the use of biocomposite materials in vehicle interior parts is increasingly seen in replacement of glass fibers reinforced composites. They are mainly used in car binnacles like door panels and dashboards. Thermoplastics such as polypropylene (PP) and biopolyesters including polylactic acid (PLA) and polybutylene succinate (PBS) are mainly used as polymer matrices. However, the highlighting of the time spent in vehicles induces more investigations on the health impact of car interior pieces [2]. Indeed, transportation is the third environment that humans attend after houses and work places, where they are subjected to indoor air pollution. Moreover, the World Health Organization (WHO) has recognized interior air pollution of vehicles as a major threat to human health [3]. Several sources like traffic emissions, tobacco smoke or interior materials can result in a poor binnacle air quality. Recently, the "Sick Car Syndrome" has been highlighted as a result of the identification of toxic Volatile Organic Compounds (VOCs) emitted by binnacle pieces [4]. They are issued from the dashboard, door panels, seat coverings and flooring materials. They can cause eye, nose and throat irritations, allergic skin reactions, headaches and fatigue. Emitted VOCs can also be responsible for olfactory annoyance and could limit end use application [5,6].

Currently, some national regulations and standardizations have been implemented to improve vehicle indoor air quality (VIAQ). Korea government has been one of the first countries to manage VIAQ guideline. They have established the notification No. 2007-539 in 2007

\footnotetext{
* Corresponding author.

E-mail address: Valerie.Desauziers@mines-ales.fr (V. Desauziers).
} 
specifying limit concentration levels for 6 substances which are benzene, toluene, formaldehyde, xylene, ethylbenzene and styrene with limit levels ranging from $30 \mu \mathrm{g} \mathrm{m}^{-3}$ for benzene to $1600 \mu \mathrm{g} \mathrm{m}^{-3}$ for ethylbenzene $[7,8]$. After that, a study made by Korea Automobile Testing \& Research Institute showed a significant concentration decrease in 5 years [9]. Car interior VOCs emissions are also coming under more scrutiny in China. Indeed, the standard GB/T 27630 implemented on 2012 is inspired from the recommendatory standard guideline for air quality assessment of passenger car issued on 2011 [10]. This applies the evaluation on binnacle air quality by proposing limit values for the previously mentioned 6 substances plus acetaldehyde and acrolein. Associations such as Japan Automobile Manufacturers Association (JAMA) and European Automobile Manufacturers Association (ACEA) recently made headway to improve VIAQ $[11,12]$. For instance, JAMA has drawn up the guideline "vehicle cabin VOC testing methods for passenger cars" for conducting the necessary VOC measurements. Nevertheless, the limit concentration levels are different between each country standard. Indeed, formaldehyde concentration limit ranges from $100 \mu \mathrm{g} \mathrm{m}^{-3}$ in Chinese and Japanese standards to $250 \mu \mathrm{g} \mathrm{m}^{-3}$ in Korean guideline. They only concern whole vehicle assessment whereas threshold values at the material scale are mostly imposed by automotive industries. In order to propose new vehicles complying with the VIAQ limit values, worldwide standards describing test methods for the determination of VOCs emissions from car trim components are already implemented. In Europe, ISO 12219 standards describe different protocols and scales for the determination of either VOCs concentrations in car indoor air or VOCs emission rate for materials [13-15].

Lots of studies dealt with pollutants emission in vehicles and the influence of different parameters on their concentrations. Most of the time, total VOCs (TVOCs) concentration is also measured, besides individual VOC levels, to evaluate indoor air quality [8,16-20]. In automotive and building industry, all VOCs whose retention times are between those of hexane and hexadecane under specific gas chromatographic conditions represent TVOCs [21]. It was shown that static conditions (parked, unventilated) favored higher TVOCs concentration in car cabins than specified driving conditions and ventilation. TVOCs level was decreased from $1980 \mathrm{\mu g} \mathrm{m}^{-3}$ in moderate-heat (almost $40^{\circ} \mathrm{C}$ ) and static conditions to $100 \mu \mathrm{g} \mathrm{m}^{-3}$ under 90 -min driving conditions in a 1997 Ford vehicle [20]. Vehicle age also plays a role. Indeed, Chien compared measured levels in new cars for specified products with levels found in literature [18]. It was observed that they could be three orders of magnitude higher than those of older cars, but they decrease over time [22]. VOCs emission is strongly temperature dependent [22] but other parameters like relative humidity and interior trim compositions have also an influence. Indeed, leather pieces emit higher quantities than fabric pieces with a big influence on toluene VIAQ concentration which can increase by $39 \%[17,18]$. The contribution of materials to the VIAQ is therefore very important. That is highlighted by a study only focused on VOCs emissions from materials [19]. Long-chain aliphatic hydrocarbons and aromatic compounds, like toluene and xylenes, were mostly identified and counted for $52 \%$ and $42 \%$ of TVOCs concentration respectively. Other chemical families like halocarbons, carbonyls and esters were also detected. This kind of study is not very widespread and to our knowledge, no work is published regarding emissions of VOCs emitted by car interior finished parts made of biocomposites.

Vegetal fibers used in biocomposites are known to be sensitive face to climatic conditions such as ultraviolet (UV) rays, high temperatures and humidity. Physico-chemical properties of natural fillers composites are thereby affected by water absorption and oxidation reactions leading to mechanical performance loss, chemical composition and visual aspect changes [23-30]. Some works described qualitative and semi-quantitative analysis of VOCs evolved from biocomposites. A study has been done on emissions of VOCs sampled by HeadSpace Solid Phase MicroExtraction (HS-SPME) after a thermal ageing of cellulose and hemp fibers reinforced polypropylene (PP) composites [31].
Different VOCs chemical families were identified such as aliphatic hydrocarbons, carboxylic acids and alcohols but also compounds specific to natural fibers like 2-furanmethanol. K.W. Kim et al. worked on the reduction of TVOCs emission from pineapple and destarched cassava flour reinforced polylactic acid (PLA) and polybutylene succinate (PBS) biocomposites by the bake-out process [16]. The study investigated the influence of temperature and baking time on TVOCs emission factor. They noted a factor increase with temperature and a decrease with baking time. Otherwise, neat PLA and PBS presented lower emission factor than loaded ones. In the same line, H.S. Kim et al. worked on the reduction of odor and VOC emissions of vegetal flour filled reinforced PLA and PBS composites by incorporating porous inorganic fillers [32]. Volatile products emissions caused by high temperature manufacturing like tridecane from the matrix and furfural from bamboo flour were decreased. Olfactometric analyses carried out on natural fillers composites allowed to understand the high responsibility of oxygenated compounds issued from both the polymer and natural fillers to unpleasant odor [5]. However, no study deals with the VOCs emissions of biocomposites under real conditions of use since the impact of natural fiber composites ageing on VOCs emission is poorly documented. Indeed, standard measurement methods (e.g. emission chamber methods) are complex to implement and time consuming for the monitoring of the temporal evolution of VOCs emissions [33,34]. As an alternative, HS-SPME is the most widely used technique for sampling VOCs emitted by polymeric materials [5,31,35-37]. Its advantages are simplicity and time saving according to short extraction times. But this method involves material destruction by cutting it in small pieces for introduction in the headspace vial. Hence, this sampling procedure is not relevant to provide quantitative data related to surface emission. The sampling methodology used for this work and previously developed in our laboratory, is based on a home-made emission cell coupled with SPME $[38,39]$. This simple and non-destructive passive sampling method allows determining the VOCs concentration at the material/air interface which is related to the emission rate by the first Fick's law of diffusion under steady state conditions [39].

This study aims to assess the impact of VOCs emitted by hemp fibers reinforced PP on air quality and the influence of material ageing on theses emissions regarding hemp fibers rate and sampling temperature. A car interior environment was simulated by exposing laboratory-made materials under windshield glass for one year. Emitted VOCs were identified over the weathering and their concentrations at the material/ air interface were determined. Results are discussed notably in terms of ageing impact, fiber contribution and health impact. For this latter, the European regulation classes of critical products according to their impact on human health and their concentrations were gathered as well as limit values already imposed, or at least advised, by VIAQ guidelines and national standards.

\section{Materials and methods}

\subsection{Materials}

Polypropylene grade H733-07 with a melt flow rate of $7.5 \mathrm{~g} / 10 \mathrm{~min}$ $\left(230^{\circ} \mathrm{C}, 2.16 \mathrm{~kg}\right.$ ) was purchased from Braskem (Sao Paulo, Brazil) and used as polymer matrix. Hemp fibers with size included in the $2-6 \mathrm{~mm}$ range were provided by AgroChanvre (Barenton, France). Their retting lasted 38 days and their cellulose, hemicelluloses, lignin and lipophilic extractives rates of $82,8,5$ and $3 \mathrm{wt} \%$ respectively were determined by successive chemical extractions based on TAPPI T264, ASTM D1104 standards. Two hemp fibers loading, $10 \mathrm{wt} \%$ (PP10) and $30 \mathrm{wt} \%$ (PP30), were tested (Table 1). Maleic anhydride grafted polypropylene (MA-g-PP) with a $1 \mathrm{wt} \%$ grafting rate, under the trademark Orevac CA100 and supplied by Arkema (France), was added at $3.1 \mathrm{wt} \%$ of PP as coupling agent. 
Table 1

Designation of materials.

\begin{tabular}{llll}
\hline & \multicolumn{2}{l}{ Composition $(w t \%)$} & \\
\cline { 2 - 4 } & PP & Hemp fibers & MA-g-PP \\
\hline PP & 100 & - & - \\
PP10 & 87.3 & 10 & 2.7 \\
PP30 & 67.9 & 30 & 2.1 \\
\hline
\end{tabular}

\subsection{Process conditions}

Prior to extrusion, hemp fibers and MA-g-PP have been dried for $15 \mathrm{~h}$ at $60^{\circ} \mathrm{C}$ to remove residual water. Granules of PP and MA-g-PP were mixed with hemp fibers in a BC21 Clextral co-rotating twin-screw extruder ( $\mathrm{L} / \mathrm{D}=36$ with $\mathrm{D}=25 \mathrm{~mm}$ ) (Clextral, France) with the following temperature profile 190-190-190-180-175-175-175 ${ }^{\circ} \mathrm{C}$ from feed to die and a screw speed of $220 \mathrm{rpm}$. Then, pellets were dried in an aircirculating oven for 3 days at $60^{\circ} \mathrm{C}$. Finally, extruded pellets were injection molded into specimens in a Krauss Maffei KM50-T180CX (Krauss Maffei, Germany) at $210^{\circ} \mathrm{C}$ with an injection speed of $30 \mathrm{~cm}^{3} \mathrm{~s}^{-1}$. Square samples of $100 \times 100 \times 2 \mathrm{~mm}^{3}$ were obtained. Vegetal fibers pellets were formulated by pressing them in prontopress2 device (Strues, France) into 25-mm diameter pellets.

\subsection{Weathering}

Square samples were exposed in the South West of France (Pau) under flat windshield glass to simulate car interior environment according to ISO 877-2:2011 standard (Fig. 1). The exposition panels were oriented towards South at $45^{\circ}$ with the ground. Interior environment was naturally ventilated thanks to holes located at the top and bottom of the stainless steel boxes $2 \mathrm{~h}$ per day. The exposure started in September 2015 and finished in September 2016 in order to study longterm ageing effects. Temperature $\mathrm{T}\left({ }^{\circ} \mathrm{C}\right)$ and relative humidity $\mathrm{RH}(\%)$ were monitored (Fig. 2). The maximum temperature and relative humidity values reached over the weathering were respectively $89^{\circ} \mathrm{C}$ and $95 \%$ whereas the minimum values were $-5{ }^{\circ} \mathrm{C}$ and $3 \%$. Three samples of each material PP, PP10 and PP30 taken after 1, 2, 3, 6, 9 and 12 months of exposition were analyzed at the laboratory.

\subsection{Sampling and analytical methodology}

VOCs were sampled according to a passive sampling method previously developed (Fig. 3). It consists of two steps: firstly, an emission $320-\mathrm{mL}$ glass cell is deposited on the material in order to isolate its

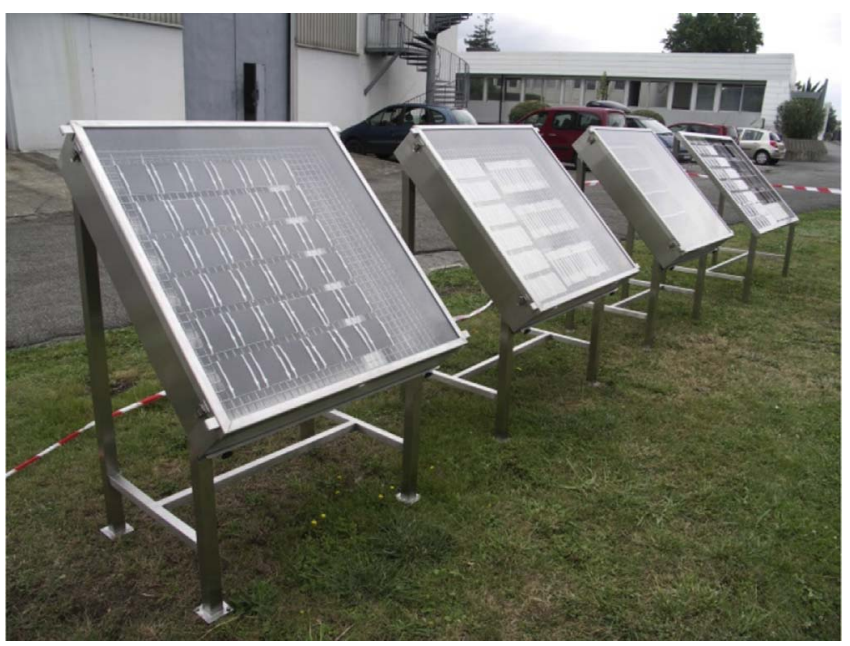

Fig. 1. Under windshield glass exposure racks. surface, the sampled area being $50 \mathrm{~cm}^{2}$. Then, VOCs are emitted in the cell volume until reaching a constant air concentration. Two hours are required to reach material/air equilibrium [38]. This sampling step was carried out at two temperatures, 23 and $80{ }^{\circ} \mathrm{C}$, in order to reflect ambient and extreme conditions found in cars. Then, a Solid Phase MicroExtraction (SPME) fiber is introduced via a septum in the glass cell to extract emitted VOCs (Fig. 3). Then, the fiber was thermally desorbed in a Varian CP-3800 gas chromatograph (GC) injector. A $1200 \mathrm{Q}$ quadrupole mass spectrometer (MS) was used for identification whereas a flame ionization detector (FID) (Varian, Les Ulis, France) was used for quantification. Separation was achieved using a polydimethylsiloxane (PDMS) $5 \%$ phenyl capillary column of $60 \mathrm{~m} \times 0.25 \mathrm{~mm}$ i.d. $\times 1 \mu \mathrm{m}$ film thickness. The complete analytical procedure is detailed elsewhere [40].

Two different analyses were performed on non-weathered and weathered samples: VOCs screening to identify and quantify the widest range of emitted compounds, and specific analysis of formaldehyde and acetaldehyde which are classified as CMR [41]. For VOCs screening, a polydimethylsiloxane-divinylbenzene-carboxen fiber (PDMS/DVB/ CAR, $50 / 30 \mu \mathrm{m}$ ) was selected. For formaldehyde and acetaldehyde, a polydimethylsiloxane-divinylbenzene (PDMS/DVB, $65 \mu \mathrm{m}$ ) fiber impregnated with $O$-(2,3,4,5,6-pentafluorobenzyl)hydroxylamine hydrochloride (PFBHA) (Fluka, Brucks, Switzerland) was used [40,42]. The two SPME fibers were purchased from Supelco (Bellefonte, USA). For the two fibers, for $23^{\circ} \mathrm{C}$ sampling, an extraction time of $20 \mathrm{~min}$ was chosen from previous work [43]. At $80^{\circ} \mathrm{C}$, an extraction time of $5 \mathrm{~min}$ was determined as a good compromise between sensitivity and shorttime sampling. All samplings were conducted in triplicates to evaluate the measurement repeatability.

This methodology allows determining the VOCs concentrations at the material/air interface (also called surface concentration) which is related to the emission rate through the First Fick law of diffusion $[38,39]$.

In order to determine the contribution of vegetal fibers in major VOCs emissions from biocomposites, qualitative analysis of VOCs emission of vegetal fibers pellets was carried out. About $2 \mathrm{~g}$ of samples of nonweathered and two-month weathered pellets were analyzed by headspace-SPME in $250 \mathrm{~mL}$ glass vials (Entech Instruments, Simi Valley, USA). The sampling was carried out for $2 \mathrm{~h}$ at $80^{\circ} \mathrm{C}$ and the analytical conditions were the same as for surface emission characterization.

\subsection{Quantitative analysis}

For the screening analysis using PDMS-DVB-CAR fiber, VOCs were quantified as toluene equivalent using FID response since it is proportional to the effective carbon atoms number in the molecule [20]. Standard gas of toluene was generated by a continuous syringe injection system supplied by Calibrage (Saint Chamas, France) equipped with a syringe pump (PHD 2000, Harvard Apparatus, Les Ulis, France) [43]. Covered toluene concentrations ranged from 17 to $388 \mu \mathrm{g} \mathrm{m}^{-3}$ for the 20 min-sampling and $67-1553 \mu \mathrm{g} \mathrm{m}^{-3}$ for the $5 \mathrm{~min}$-sampling. Furfural and 2-furanmethanol, compounds specific to hemp fibers and listed as CMR substances [41] were specifically quantified. Standard gases were also generated by a continuous syringe injection, as described above. For the specific analysis of formaldehyde and acetaldehyde by PDMS/ DVB fiber impregnated with PFBHA, standard gases were generated according to the permeation method [44]. The device used was supplied by Calibrage (Saint Chamas, France). For the two SPME methods, the Limits of Detection (LOD) are in the $\mu$ g. $\mathrm{m}^{-3}$ order level for the 20min sampling and are around $10 \mu \mathrm{g} \mathrm{m}^{-3}$ for 5-min sampling.

\section{Results and discussion}

The detailed results for surface concentrations of individual VOCs emitted by neat PP and biocomposites before and after weathering for the two sampling temperatures are presented in Table 2. 

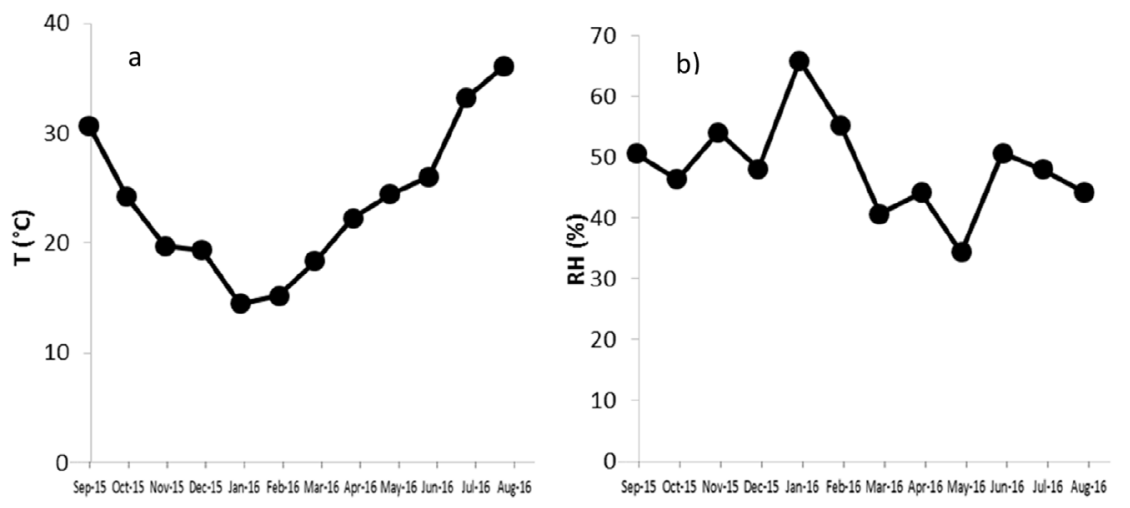

Fig. 2. Average monthly temperature $\left({ }^{\circ} \mathrm{C}\right)(\mathrm{a})$ and relative humidity (\%) (b) values in stainless steel boxes.

3.1. VOCs emissions at non-weathered state: impact of process and sampling conditions

For non-weathered PP, PP10 and PP30 analyzed at $23^{\circ} \mathrm{C}$ by PDMS/ DVB/CAR fiber, no VOC was detected. As the limits of detection for surface concentration are below the $\mu \mathrm{g} \cdot \mathrm{m}^{-3}$ level for these sampling conditions, this means that non-weathered PP, PP10 and PP30 can be considered as non-emissive materials at ambient temperature.

Contrary to $23^{\circ} \mathrm{C}$, some VOCs were detected at $80^{\circ} \mathrm{C}$ (Fig. 4 and Table 2). Thus, as expected, a higher temperature promoted the emission of volatile products. Those compounds may be generated by the thermo-oxidative degradation during the extrusion and injection molding process and/or by the $2 \mathrm{~h}$ sampling at $80^{\circ} \mathrm{C}$. Indeed, it was reported that hemp fibers are sensitive even at $70{ }^{\circ} \mathrm{C}$ [31].

PP mainly emitted $\mathrm{C}_{9}-\mathrm{C}_{15}$ branched and linear aliphatic hydrocarbons arising from the PP chains (they are gathered into groups having same carbon atoms number in Table 2). These products were caused by either polymerization defects or thermal degradation of polymer chains during processing or sampling at $80^{\circ} \mathrm{C}$. A few oxygenated compounds (alcohols, ketones, aldehydes) were also identified due to the thermo-oxidation of polymer chains.

The global VOCs surface concentration increased with the hemp fibers loading from $6851 \pm 595 \mu \mathrm{g} \mathrm{m}^{-3}$ for neat PP to $9880 \pm 979 \mu \mathrm{g} \mathrm{m}^{-3}$ for PP30 (Fig. 4). So biocomposites were more subjected to thermal degradation than PP. The concentration of oxygenated products (alcohols, carboxylic acids, ketones and aldehydes) also increased with the fiber loading to the detriment of alkanes emitted by the polymer. Some of these oxygenated compounds originated from PP: for example, levels of acetone and 4-hydroxy-4-methyl-2-pentanone emitted by non-weathered PP, PP10 and PP30 are comparable (Table 2). Thus, it can be supposed that oxidized PP chains mainly contribute to the total level of these two ketones. However, oxygenated compounds specific to vegetal fibers decomposition are predominant in global VOCs emission from biocomposites. These VOCs are referred in Table 2 with asterisk symbols when they are detected in qualitative analysis of vegetal fibers pellets. For example, furanones were emitted at the $\mathrm{mg} \cdot \mathrm{m}^{-3}$ level by PP30, but also phenolic and nitrogen containing products (azines) at $400 \mu \mathrm{g} \mathrm{m}^{-3}$ and $60 \mu \mathrm{g} \mathrm{m}^{-3}$ respectively (Table 2). All cyclic products are also known to be issued from vegetal fibers [45-47]. Moreover, several linear carboxylic acids and aldehydes (hexanoic acid, heptanoic acid, octanal and nonanal) were only identified for biocomposites and vegetal fibers pellets, which suggests that these VOCs only resulted from vegetal fibers. Some VOCs identified for biocomposites but non-identified for vegetal fiber pellets, such as 2nonenal, can be issued from prodegrading effect of fibers which provokes depolymerization.

\subsection{VOCs emissions during weathering: impact of climatic conditions}

For all materials analyzed at a sampling temperature of $23^{\circ} \mathrm{C}$, the VOCs concentration increased after one-year weathering, but in a larger proportion for biocomposites. VOCs level reached $892 \pm 183 \mu \mathrm{g} \mathrm{m}^{-3}$ for PP30 whereas it only reached $73 \pm 14 \mu \mathrm{g} \mathrm{m}^{-3}$ for neat PP after one year (Table 2). This means that weathering affected more biocomposites stability than PP one. Ketones (acetone and 2,4-pentanedione) and carboxylic acids (acetic and propionic acids) were increasingly detected during the weathering (Table 2). These oxygenated products come from the polymer chains and hemp fibers oxidation under high temperatures and UV rays, key factors favoring free-radical mechanisms involving reactions with oxygen from the atmosphere [48]. Propionic acid was only emitted by biocomposites, suggesting that it was only issued from hemp fibers degradation. This will be confirmed in the following part.

In view of the higher number of VOCs detected after $80^{\circ} \mathrm{C}$ sampling than at $23^{\circ} \mathrm{C}$ one, the study all along the ageing is focalized to the analysis carried out at the highest sampling temperature. Hence, the evolution of concentrations of VOCs sampled at $80^{\circ} \mathrm{C}$ all along the ageing for PP, PP10 and PP30 is illustrated by main chemical family in Fig. 5.

The global concentration of VOCs emitted by PP did not significantly vary. Thus, the weathering did not greatly influence the global level. $\mathrm{C}_{9}-\mathrm{C}_{15}$ alkanes were among the predominant VOC species sampled all along the weathering. However, $C_{9}, C_{10}$ and $C_{11}$ short

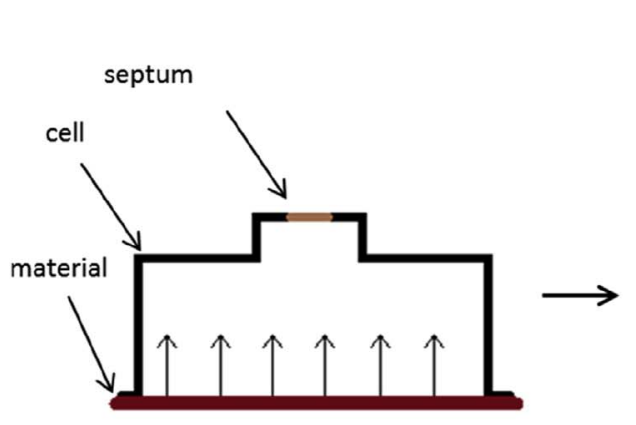

A

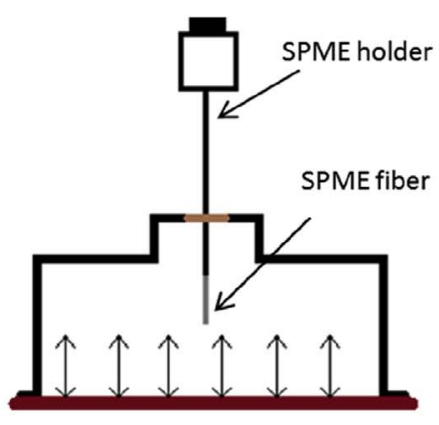

Fig. 3. Schematic representation of the emission cell-SPME system (A: establishment of the material/air equilibrium at $23^{\circ} \mathrm{C}$ or $80^{\circ} \mathrm{C}$, B: SPME sampling of VOCs). 
Table 2

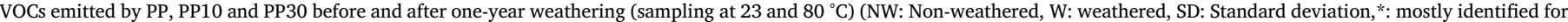

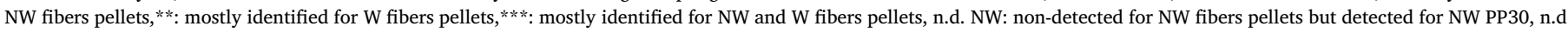
$\mathrm{W}$ : non-detected for W fibers pellets but detected for W PP30).

Surface concentration \pm SD ( $\mu$ g.m-3)

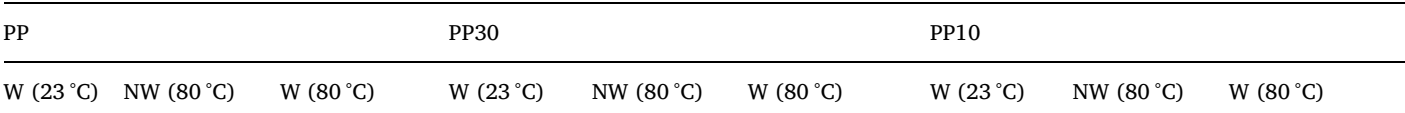

Aliphatic hydrocarbons

$\mathrm{C}_{9}$

$\mathrm{C}_{10}$

$\mathrm{C}_{11}$

$\mathrm{C}_{12}$

$\mathrm{C}_{13}$

$\mathrm{C}_{14}$

$\mathrm{C}_{15}$

Ketones

Acetone*

1-hydroxy-2-propanone*

2,3-butanedione (n.d. NW)

2-pentanone (n.d. W)

3-hydroxy-2-butanone*

3-penten-2-one (n.d. W)

2(5H)-furanone (n.d. NW)

Butyrolactone***

Cyclopentene-1,3-dione (n.d. NW)

5-methyl-2(5H)-furanone (n.d. NW)

Cyclopentane-1,2-dione

5-methyl-2(3H)-furanone

Pentane-2,4-dione**

4-hydroxy-2-pentanone (n.d. W)

1-(1H-pyrrol-2-yl)-ethanone (n.d. NW)

1-(2-furanyl)-ethanone

3-methyl-2,5-furandione

2,5-dihydro-3,5-dimethyl-2furanone

3-methyl-1,2-cyclopentanedione (n.d. NW)

3-methyl-3-hexen-2-one

1-(3,3-dimethyloxiranyl)ethanone**

3,4-epoxy-3-ethyl-2,3-butanone 2,5-hexanedione**

1-acetyloxy-2-propanone*

4-hydroxy-4-methyl-2-pentanone***

6-methyl-5-hepten-2-one

4-methoxy-2-heptanone**

Maltol

Levoglucosenone (n.d. NW)

3,4-dimethyl-2,5-furanedione

2,4,4-trimethylbut-2-enolide**

3-ethyl-2-hydroxy-2-cyclopenten-1one

5-hydroxy-4,5-dimethyl-2,5-(2H)furanone

3,3-dimethyl-2,4-pentanedione (n.d. W)

1-(2,4-dimethyl-furan-3-yl)ethanone**

3-acetonylcyclopentanone $* * *$

2,4-dihydro-5-hydroxy-3,3,5-

trimethyl-2-furanone**

4-acetonylcyclohexanone

4,6-dimethyl-2-heptanone**

2-methyl-3-nonanone (n.d. W)

3,6-dimethyloctan-2-one

6,10-dimethyl-5,9-undecadien-2one*

4,4,5,5-tetramethyl-2,7-octanedione

Carboxylic acids

Acetic acid*

Propionic acid*

Crotonic acid* (n.d. W)

Methacrylic acid

Hexanoic acid*

$\begin{array}{ll}65 \pm 5 & 179 \pm 8 \\ 786 \pm 14 & 1625 \pm 367 \\ 550 \pm 64 & 1061 \pm 92 \\ 820 \pm 27 & 692 \pm 116 \\ 1768 \pm 50 & 1241 \pm 240 \\ 339 \pm 117 & 140 \pm 16 \\ 1672 \pm 50 & 771 \pm 52\end{array}$

24

$333 \pm 34$

$-$

$-$

$-$

$-$

$-$

$-$

-

$-$

$101 \pm 17$

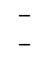

\section{$-$}

$366 \pm 11$

$87 \pm 10$

$-$

$145 \pm 19$

$97 \pm 4$

- $118 \pm 32$

-

$72 \pm 9$

$1314 \pm 20$

$\begin{array}{ll}- & 754 \pm 118\end{array}$

$157 \pm 55$

$1063 \pm 243$

$1899 \pm 70$

$303 \pm 48$

$277 \pm 63$

$361 \pm 81$

$110 \pm 9$

$265 \pm 56$

$48 \pm 0$

$172 \pm 48$

$\begin{array}{ll}30 \pm 4 & 26 \pm 1 \\ - & - \\ - & - \\ - & - \\ - & 24 \pm 8\end{array}$
$542 \pm 61$
-
-
$120 \pm 70$
$81 \pm 25$
$667 \pm 152$

$56 \pm 16$$$
\text { - }
$$

$\begin{array}{ll}397 \pm 62 & 18304 \pm 620 \\ - & 1403 \pm 3 \\ - & 3332 \pm 612 \\ - & - \\ 130 \pm 8 & 213 \pm 48\end{array}$

$$
\begin{aligned}
& 5 \\
& 291 \\
& 575 \\
& 123 \\
& 238 \\
& 1388 \\
& 15 \\
& 12 \\
& 31 \\
& - \\
& - \\
& - \\
& 157 \\
& 123 \\
& - \\
& 27 \\
& 42 \\
& 53 \\
& - \\
& - \\
& 87 \\
& \\
& 27 \\
& - \\
& - \\
& \hline
\end{aligned}
$$

$590 \pm 25$

$575 \pm 8$

$1230 \pm 136 \quad 833 \pm 39$

$238 \pm 20 \quad 139 \pm 3$

$1388 \pm 26$

$15 \pm 1 \quad 1074 \pm 22$

$122 \pm 15 \quad 911 \pm 109$

$31 \pm 5$ -

$-\quad 453 \pm 28$

$\begin{array}{ll}157 \pm 10 & - \\ 123 \pm 9 & 295 \pm 5\end{array}$

$-$

$27 \pm 7$

$42 \pm 1$

$53 \pm 16$

$-$

$87 \pm$

$8 \pm 211$

$27 \pm 2$

$-\quad 746 \pm 21$

$218 \pm 8$

$42 \pm 6$

$127 \pm 2$

$127 \pm 2$
$-\quad 872 \pm 5$

- $\quad 313 \pm 6$

$521 \pm 40$

$147 \pm 17 \quad 451 \pm 10$

$79 \pm 15 \quad 3592 \pm 82$

$-$

$189 \pm 6$

$43 \pm 2 \quad-$

$68 \pm 9-$

$1990 \pm 146$

$-$

$968 \pm 44$

$135 \pm 1$

$1807 \pm 149$

$2324 \pm 120$

$330 \pm 18$

$333 \pm 5$

$278 \pm 2$

$85 \pm 11$

$344 \pm 4$

$212 \pm 26$

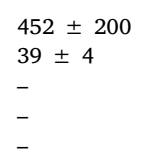

179

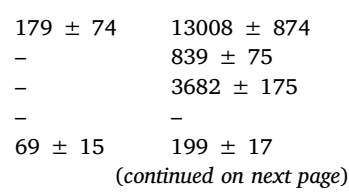




\begin{tabular}{|c|c|c|c|c|c|c|c|c|c|}
\hline & \multicolumn{9}{|c|}{ Surface concentration \pm SD ( $\mu \mathrm{g} \cdot \mathrm{m}-3)$} \\
\hline & \multicolumn{3}{|l|}{ PP } & \multicolumn{3}{|l|}{ PP30 } & \multicolumn{3}{|l|}{ PP10 } \\
\hline & $\mathrm{W}\left(23^{\circ} \mathrm{C}\right)$ & $\mathrm{NW}\left(80^{\circ} \mathrm{C}\right)$ & $\mathrm{W}\left(80^{\circ} \mathrm{C}\right)$ & $\mathrm{W}\left(23^{\circ} \mathrm{C}\right)$ & $\mathrm{NW}\left(80^{\circ} \mathrm{C}\right)$ & $\mathrm{W}\left(80^{\circ} \mathrm{C}\right)$ & $\mathrm{W}\left(23^{\circ} \mathrm{C}\right)$ & $\mathrm{NW}\left(80^{\circ} \mathrm{C}\right)$ & $\mathrm{W}\left(80^{\circ} \mathrm{C}\right)$ \\
\hline Benzoic acid & - & - & - & - & $45 \pm 6$ & - & - & $44 \pm 13$ & - \\
\hline Heptanoic acid* & - & - & - & - & - & $115 \pm 15$ & - & - & $87 \pm 9$ \\
\hline Octanoic acid* & - & $25 \pm 7$ & $62 \pm 4$ & - & $70 \pm 10$ & $201 \pm 14$ & & $43 \pm 22$ & $238 \pm 1$ \\
\hline 7-oxooctanoic acid & - & - & - & - & - & $271 \pm 26$ & - & - & $389 \pm 2$ \\
\hline Nonanoic acid* & - & - & - & - & - & $266 \pm 27$ & - & - & $304 \pm 2$ \\
\hline Dehydroacetic acid & - & - & - & - & - & $473 \pm 55$ & - & - & $618 \pm 41$ \\
\hline \multicolumn{10}{|l|}{ Aldehydes } \\
\hline Methacrolein** & - & - & - & - & - & $291 \pm 44$ & - & - & $107 \pm 76$ \\
\hline Furfural* & - & - & - & - & $1611 \pm 20$ & - & - & $703 \pm 15$ & - \\
\hline Furfuryl formate & - & - & - & - & $38 \pm 4$ & - & - & - & - \\
\hline Furfuryl acetate* & - & - & - & - & $43 \pm 4$ & - & - & - & - \\
\hline 5-methylfurfural* & - & - & - & - & $660 \pm 30$ & - & - & $245 \pm 14$ & - \\
\hline Benzaldehyde* & - & - & - & & $93 \pm 0$ & $77 \pm 10$ & - & $28 \pm 11$ & \\
\hline Octanal $^{* * *}$ & - & $26 \pm 6$ & $51 \pm 1$ & - & $29 \pm 7$ & $54 \pm 15$ & - & $27 \pm 5$ & $41 \pm 3$ \\
\hline Nonanal ${ }^{* * *}$ & - & - & - & - & $160 \pm 28$ & $94 \pm 14$ & & $259 \pm 27$ & $149 \pm 2$ \\
\hline 2,4-dimethyl-pentanal & - & - & - & - & - & $64 \pm 1$ & - & - & $89 \pm 9$ \\
\hline 2-nonenal (n.d. NW) & - & & & - & $65 \pm 7$ & - & - & $27 \pm 10$ & - \\
\hline Decanal* & - & $89 \pm 28$ & $135 \pm 1$ & - & $119 \pm 30$ & $121 \pm 16$ & - & $128 \pm 12$ & $146 \pm 1$ \\
\hline $\begin{array}{l}\text { 1-(1,1-dimethylethyl)methyl-2- } \\
\text { propenal (n.d.W) }\end{array}$ & - & - & - & - & - & $741 \pm 71$ & - & - & $882 \pm 42$ \\
\hline Dodecanal* & - & $40 \pm 9$ & $57 \pm 30$ & - & $63 \pm 3$ & - & - & $53 \pm 8$ & - \\
\hline 1H-pyrrole-2-carboxaldehyde* & - & - & - & - & $121 \pm 22$ & - & - & $79 \pm 6$ & - \\
\hline Vanillin & - & - & - & - & $159 \pm 27$ & - & - & - & - \\
\hline \multicolumn{10}{|l|}{ Alcohols } \\
\hline 2-methyl-2-propen-1-ol (n.d. W) & - & - & - & & - & $602 \pm 110$ & - & - & $293 \pm 41$ \\
\hline 2-furanmethanol* & - & - & - & - & $2319 \pm 176$ & - & - & $641 \pm 89$ & - \\
\hline 2-ethyl-1-hexanol* & - & $52 \pm 11$ & $52 \pm 4$ & - & $79 \pm 9$ & $176 \pm 17$ & - & $101 \pm 7$ & $148 \pm 1$ \\
\hline 2-isopropyl-5-methyl-1-heptanol & - & $206 \pm 9$ & $214 \pm 1$ & - & $44 \pm 1$ & - & - & $166 \pm 15$ & - \\
\hline 4-methyl-1,6-heptadien-4-ol & - & - & - & - & - & $832 \pm 46$ & - & - & $889 \pm 23$ \\
\hline 2-ethyldecanol & - & - & $62 \pm 1$ & - & - & - & - & - & - \\
\hline Tridecanol & - & $63 \pm 6$ & $50 \pm 4$ & - & - & - & - & - & - \\
\hline 2-methyltridecanol & - & $89 \pm 50$ & $26 \pm 1$ & - & - & - & - & $59 \pm 9$ & - \\
\hline \multicolumn{10}{|l|}{ Phenols } \\
\hline 3,5-dimethylphenol** & - & - & - & - & - & $471 \pm 75$ & - & - & $642 \pm 2$ \\
\hline 2-methoxy-4 vinylphenol* & - & - & - & - & $195 \pm 28$ & - & - & - & - \\
\hline 2,6-bis(1,1-dimethylethyl)phenol & - & $124 \pm 7$ & $195 \pm 22$ & - & $163 \pm 16$ & $120 \pm 11$ & - & $392 \pm 60$ & $158 \pm 7$ \\
\hline \multicolumn{10}{|l|}{ Furans } \\
\hline $\begin{array}{l}\text { 2,4-dimethylfuran/2,5- } \\
\text { dimethylfuran** }\end{array}$ & - & - & $82 \pm 14$ & - & - & $2462 \pm 143$ & - & - & $990 \pm 82$ \\
\hline \multicolumn{10}{|l|}{ Azines } \\
\hline Methylpyrazine* & - & - & - & - & $25 \pm 2$ & - & - & - & - \\
\hline $\mathrm{N}$-acetyl-4(H)-pyridine & - & - & - & - & $38 \pm 4$ & - & - & - & - \\
\hline \multicolumn{10}{|l|}{ Non-quantified (N.Q.)- } \\
\hline $\mathrm{C}_{15}(1 \mathrm{VOC})$ & - & N.Q. & N.Q. & - & N.Q. & N.Q. & - & N.Q. & N.Q. \\
\hline $\begin{array}{l}\text { 2,6-di-butyl-2,5-cyclohexadiene-1,4- } \\
\text { dione }\end{array}$ & - & N.Q. & N.Q. & - & N.Q. & N.Q. & - & N.Q. & N.Q. \\
\hline \multicolumn{10}{|l|}{ Total (sum of concentrations) } \\
\hline & $73 \pm 14$ & $6854 \pm 490$ & $8343 \pm 1260$ & $892 \pm 183$ & $9965 \pm 872$ & $56526 \pm 9593$ & $526 \pm 211$ & $8618 \pm 797$ & $51700 \pm 2700$ \\
\hline
\end{tabular}

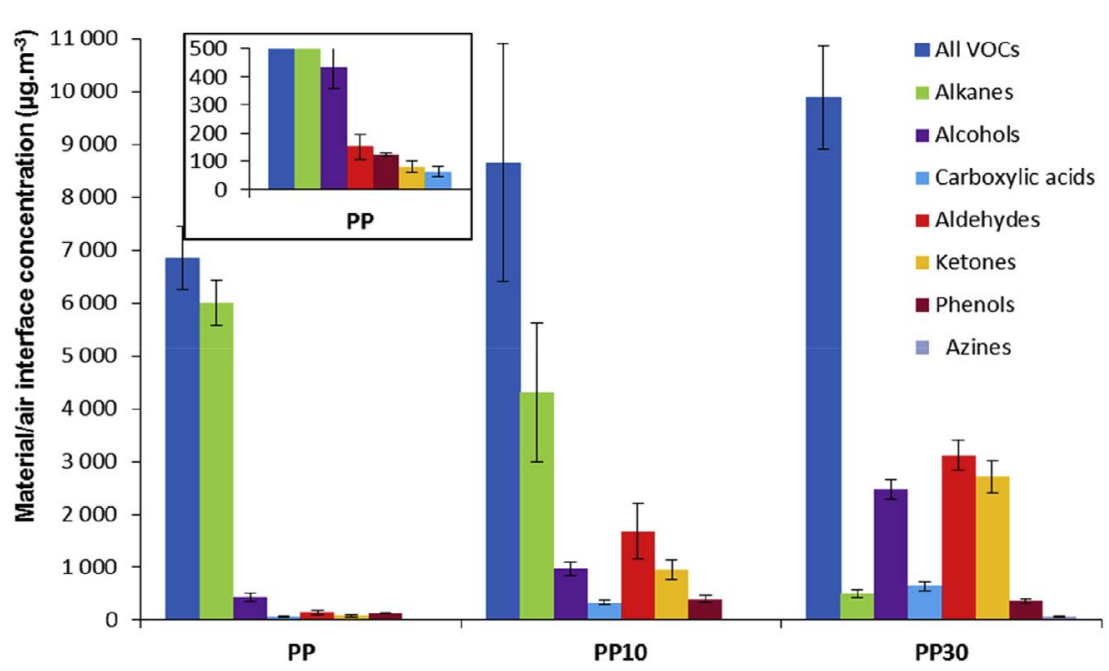

Fig. 4. Families of VOCs emitted by non-weathered PP, PP10 and PP30. 


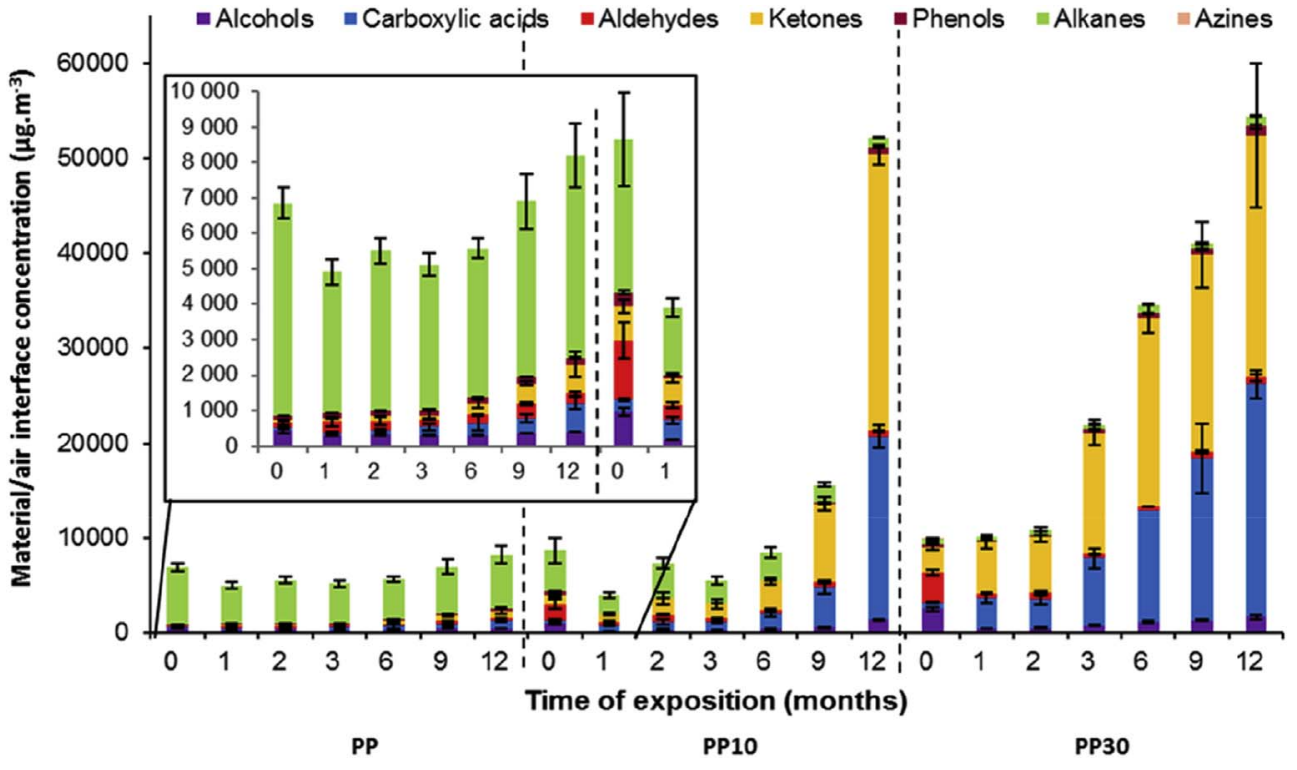

alkanes concentrations increased after the ageing to the detriment of $\mathrm{C}_{14}$ and $\mathrm{C}_{15}$ (Table 2). This result suggests that the weathering induced polymer chain scissions which favored shorter chains formation. Also, ketones, aldehydes and carboxylic acids proportion increased after oneyear weathering of PP and represented $28 \%$ of VOCs surface concentration (Fig. 5). In addition, the substituted phenols detected in virgin PP identified as 2,6-bis(1,1-dimethylethyl)phenol and 2,6-dibutyl-2,5-cyclohexadiene-1,4-dione were derived from the Irganox L140 and Irganox $1010^{\circ}$ antioxidants respectively probably incorporated during manufacturing process to stabilize the polymer and prevent its thermo-oxidation (Table 2) [31].

PP10 and PP30 emitted VOCs at higher concentrations than PP over the exposition (Fig. 5): their global surface concentration drastically increased by 6 and 5 times respectively (Table 2).

As shown in Fig. 5, PP10 presented a same VOCs emission profile as PP30 after 1 year whereas it mainly emitted alkanes from the polymer matrix at non-aged state. This suggests that hemp fibers proportion on PP10 surface increased with the weathering time to the detriment of polymer matrix. Moreover, studies reporting the surface topography evolution during an ageing showed a roughness increase on natural fillers composites surface caused by fillers proportion increase [23,30].

As at non-weathered state, PP30 emitted alkanes at lower concentrations than PP due to a lower proportion of virgin PP in the biocomposite. However, contrary to $\mathrm{PP}, \mathrm{C}_{13}, \mathrm{C}_{14}$ and $\mathrm{C}_{15}$ alkanes levels increased during the exposition of PP30 (Table 2). This can be due to hindrance of polymer derivatives emission at non-weathered state caused by the presence of physical entanglement of hemp fibers. Then, the degradation of vegetal fibers during the weathering led to fibers network overthrow inducing the increase of $\mathrm{C}_{13}, \mathrm{C}_{14}$ and $\mathrm{C}_{15}$ alkanes emission with weathering time.

In addition to alkanes coming from polymer, oxygenated compounds were emitted by biocomposites. The main oxygenated compounds contributors are ketones and carboxylic acids. These latter represented $37 \%$ and $45 \%$ of total concentration for one-year weathered PP10 and PP30 respectively. As shown by the specific analysis of aged hemp fibers pellets (asterisks in Table 2), these compounds are mainly issued from the fibers decomposition. Some major substances such as pentane-2,4-dione, 1-(2,4-dimethyl-furan-3-yl)-ethanone and nonanal emitted by one-year weathered biocomposites were proved to come from fibers degradation since they were also identified after analysis of the aged fibers pellets. These results confirm that the drastic increase of oxygenated compounds over the weathering is mainly due to vegetal fibers oxidation. Indeed, the presence of chromophoric structures in natural fibers enhances energy absorption in UV rays range so that their reactivity is favored $[26,49]$, inducing hemp fibers degradation and byproducts emission. As for non-weathered state, all cyclic compounds are known to originate from fibers decomposition [45-47]. However, some VOCs, such as crotonic acid, 2-pentanone, 4-hydroxy-2-pentanone, 3penten-2-one, 2-methyl-2-propen-1-ol and 1-(1,1-dimethylethyl)methyl-2-propenal, present in one-year weathered PP30, were not identified in aged fibers pellets analysis. This demonstrates possible interactions between polymer and hemp fibers and/or prodegrading effect implying degradation mechanisms different from those specific to fibers and PP separately.

Among the oxygenated compounds specifically emitted by the biocomposites, furanic and phenolic substances are quantified at high concentration levels (almost $6900 \mu \mathrm{g} \mathrm{m}^{-3}$ and $470 \mu \mathrm{g} \mathrm{m} \mathrm{m}^{-3}$ respectively for one-year weathered PP30). They are of particular interest as they are known to be issued from holocellulose and lignin which compose the hemp fibers. Therefore, the next section (3.3) focuses on these compounds.

\subsubsection{Cellulose and hemicelluloses by-products}

Some furanic compounds are specifically emitted by the biocomposites both at non-weathered and weathered states. The evolution of these cyclic ketones issued from cellulose and hemicelluloses degradation was individually followed over the exposition. The surface concentration variations measured for the highest fiber loading biocomposite (PP30) analyzed at $80^{\circ} \mathrm{C}$ are represented in Fig. 6 for furan and cycloketone products.

Some products like furfural $\left(1611 \pm 20 \mu \mathrm{g} \mathrm{m}^{-3}\right)$ and 2-furanmethanol $\left(2319 \pm 219 \mu \mathrm{g} \mathrm{m}^{-3}\right)$, emitted by unaged samples, were no longer detected after the weathering of biocomposites (Fig. 6a). These compounds originated from ring-opening of primary saccharides contained in holocellulose followed by further cyclization [45]. Other furans were emitted and mainly methyl substituted furanones appeared during weathering. After 6 months, their concentrations stagnated except for dimethylfuran, the lightest furan molecule, increasing all along the ageing. This last trend is explained by a reaction equilibrium favored towards short carbonyl fragments formation, continually increasing, rather than furanone derivatives formation. Also, the higher temperatures observed during the second half-year exposition (Fig. 2) favored low molecular weight compounds emissions due to long-term degradation. However, the rising release of dimethylfuran is due to the contribution of polymer matrix to this product emission in addition to hemp fibers [50]. As regards cyclic ketones, two acetonyl substituted 


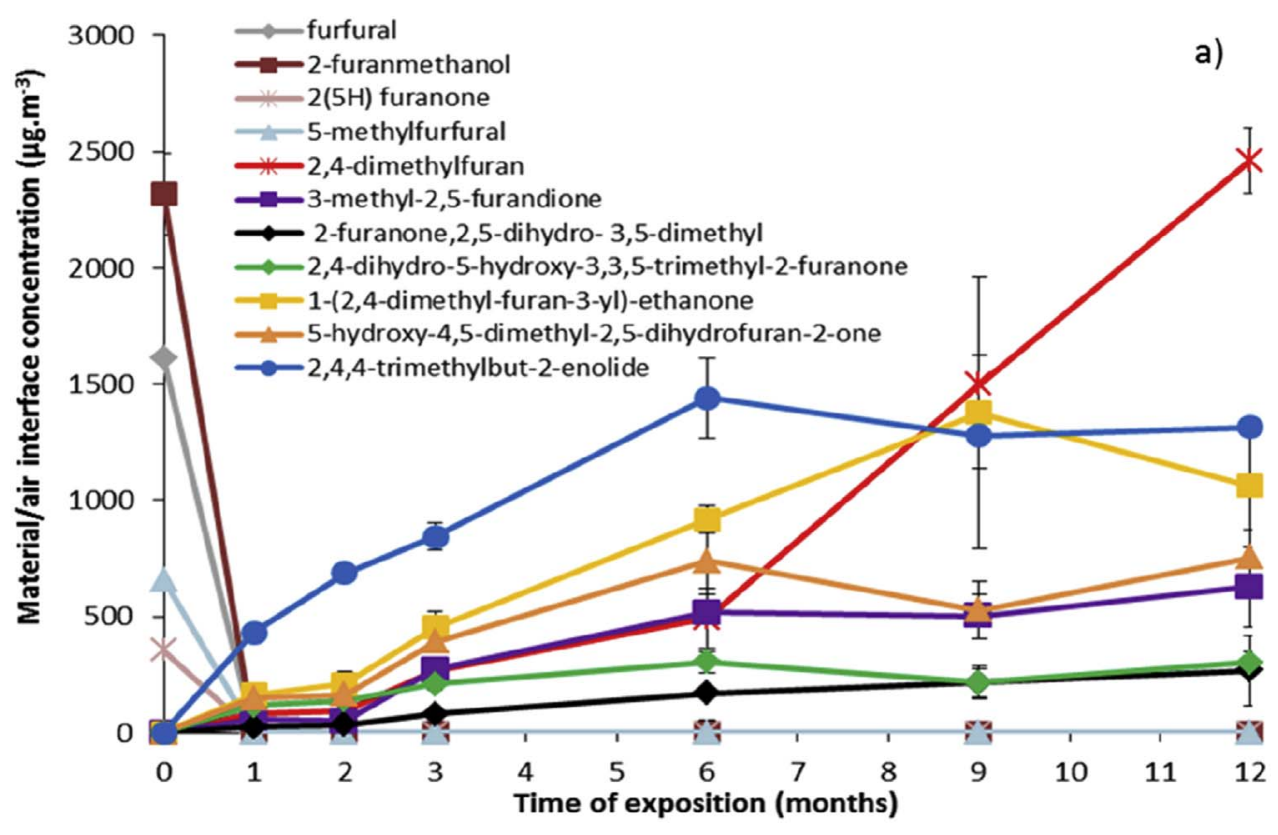

Fig. 6. Variations of major furan (a) and cyclic ketones (b) VOCs released by PP30 over the exposition (PDMS/DVB/CAR SPME fiber - sampling at $80^{\circ} \mathrm{C}$ ).

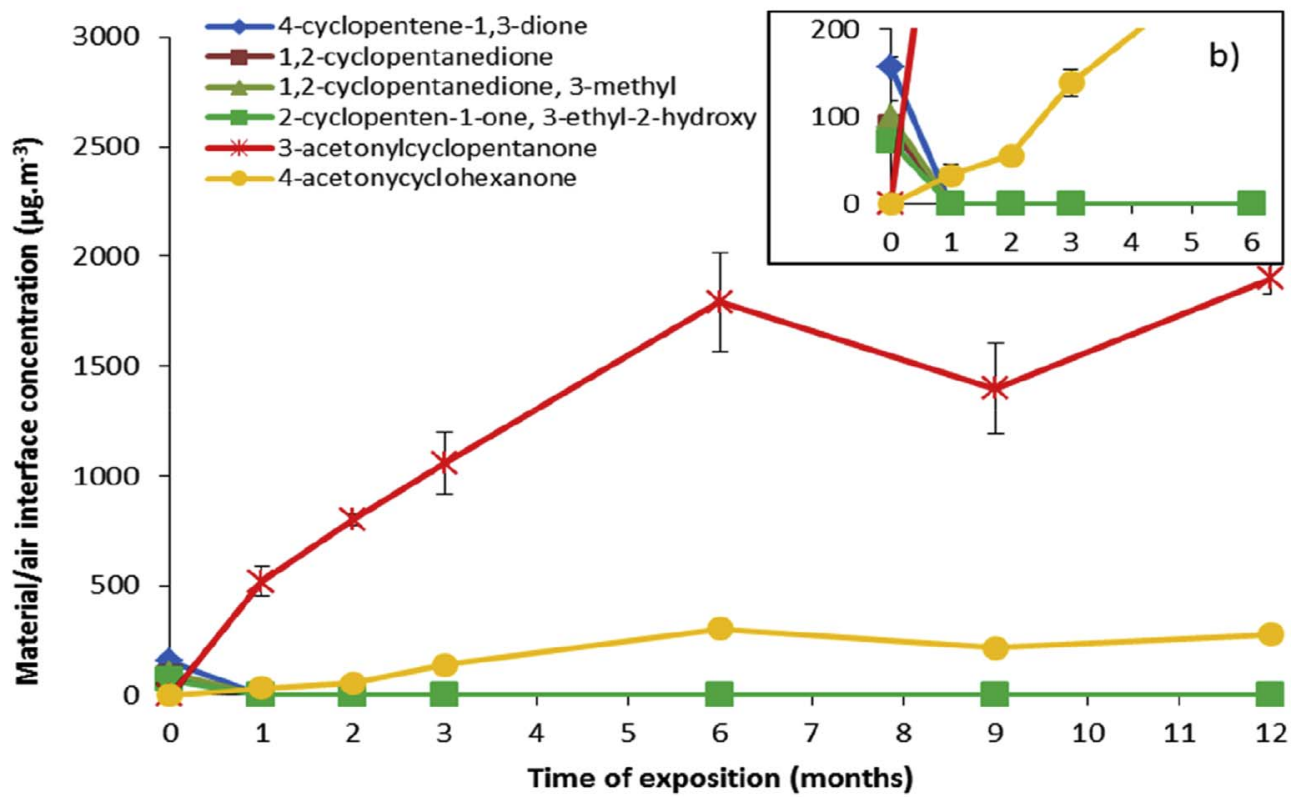

cyclic ketone substances were formed during the ageing (Fig. 6b): 3acetonylcyclopentanone was predominant among all substances belonging to this group. This molecule present in great quantity $\left(1899 \pm 70 \mu \mathrm{g} \mathrm{m}^{-3}\right.$ after 1 year) is supposed to mainly originate from cellulose source rather than hemicelluloses [46,47].

\subsubsection{Lignin by-products}

Phenolic monomeric products emitted by PP30 were linked to the thermal breakdown of lignin, amorphous cross-linked phenolic polymer contained in vegetal fibers (Fig. 7). Whatever the weathering duration, phenolic molecules concentrations are lower than carbohydrates derived VOCs. It is explained by the lower proportion of lignin present in hemp fibers, which approximately accounts for less than $10 \mathrm{wt} \%$ whereas the holocellulose part almost represents $85 \mathrm{wt} \%$ [51,52]. Moreover, hemp fibers having undergone a long retting time to facilitate separation of the fiber from the stem, it led to a lower lignin proportion since chromophores present in lignin are sensitive to retting parameters such as solar radiation [53-55].
Methoxy substituted phenols like 4-hydroxy-3-methoxybenzaldehyde (vanillin) and 2-methoxy-4-vinylphenol (4-vinylguaiacol) disappeared after weathering. These compounds were originated from a lignin primary decomposition implying primary reactions occurring in solid phase [56]. 3,5-dimethylphenol, which is an alkyl substituted aromatic ring, replaced them after ageing as secondary decomposition product. The last one involves reactions in vapor phase or heterogeneous gas/solid reactions. Indeed, bonds cleavage of preformed guaiacol structures can induce alkyl substituted phenols formation.

\subsection{Impact on indoor air quality (IAQ)}

Recently, the vehicle indoor air quality (VIAQ) has been getting extensive attention as a result of various hazardous substances detection. Hence, this part focuses on the possible toxicity or noxiousness of some identified products.

According to their well-known toxicity [21,57], formaldehyde and 


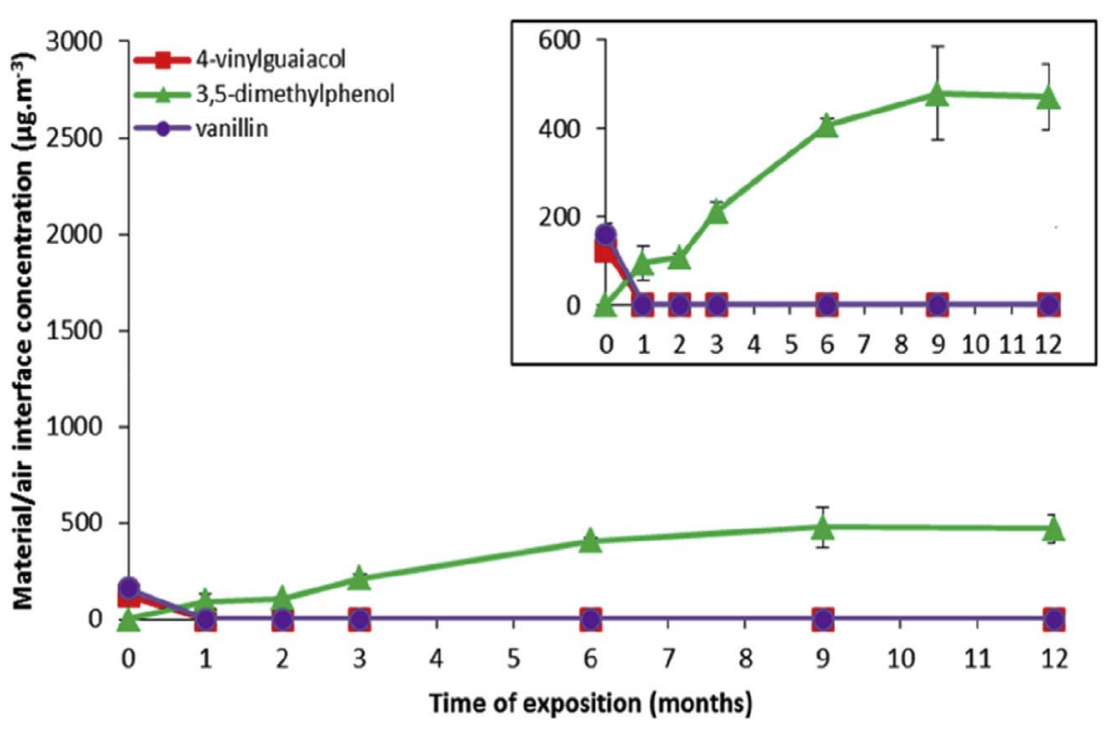

Fig. 7. Variations of phenolic VOCs released by PP30 over the exposition (PDMS/DVB/CAR SPME fiber - sampling at $80^{\circ} \mathrm{C}$ ).

acetaldehyde emissions were specifically monitored thanks to PDMSDVB fiber impregnated with PFBHA. Indeed, formaldehyde is carcinogenic to humans whereas acetaldehyde is classified in C2 category in CLP regulation meaning that it is suspected of being carcinogenic [41] (Table 3). Concentrations were measured after 0, 6 and 12 months of weathering (Fig. 8).

As for the other aldehydes (see 3.1), the concentration of these two compounds increased for all materials during the exposition, especially for PP30, reaching $20.3 \pm 0.9 \mathrm{\mu g} \mathrm{m}^{-3}$ (formaldehyde) and $39.5 \pm 0.3 \mu \mathrm{g} \mathrm{m}^{-3}$ (acetaldehyde) after one year and a $23^{\circ} \mathrm{C}$ sampling.

Furfural (2-furaldehyde) and 2-furanmethanol (furfuryl alcohol), emitted by biocomposites at high surface concentration in high-heat conditions $\left(1611 \pm 20 \mu \mathrm{g} \mathrm{m}^{-3}\right.$ and $2319 \pm 219 \mu \mathrm{g} \mathrm{m}^{-3}$ respectively for PP30), are classified in C2 category (Table 3). Nevertheless, the biocomposites weathering induced their disappearance and would thus no longer have negative effects. However, other substituted furan compounds appeared and are of concern since furan molecule is presented as a C1B M2. Also, alkanes released at high level by the polymer heated at $80^{\circ} \mathrm{C}$ are also classified in $\mathrm{C} 1 \mathrm{~B}$ category. Otherwise, phenols coming from lignin component are notified as impacting organic pollutants and are classified as of concern.

Table 4 resumes formaldehyde, acetaldehyde and TVOCs surface concentrations determined in this study. Limit values of indoor concentrations given by existing VIAQ guidelines and standards were gathered in Table 5. Only formaldehyde and acetaldehyde are concerned. It should be noticed that the data from Tables 4 and 5 cannot be directly compared. Indeed, the relationship between indoor air concentration and surface concentration of a pollutant is deduced from the first Fick's law of diffusion and is given by equation (1), considering that the studied indoor environment (e.g. the car cabin) behaves as a continuous stirred reactor operating in steady state conditions [38].

Table 3

CLP regulation of harmful substances (C1B: carcinogenic, M2: suspected to be mutagenic, C2: suspected to be carcinogenic, M3: substance of concern in reason of possible mutagenic effects).

\begin{tabular}{ll}
\hline Substances & CMR classification \\
\hline Formaldehyde & C1B M2 \\
Acetaldehyde & C2 \\
Furan & C1B M2 \\
2-furaldehyde & C2 \\
Furfuryl alcohol & C2 \\
$\mathrm{C}_{12}-\mathrm{C}_{26}$ branched and linear alkanes & $\mathrm{C} 1 \mathrm{~B}$ \\
Phenols & M3 \\
\hline
\end{tabular}

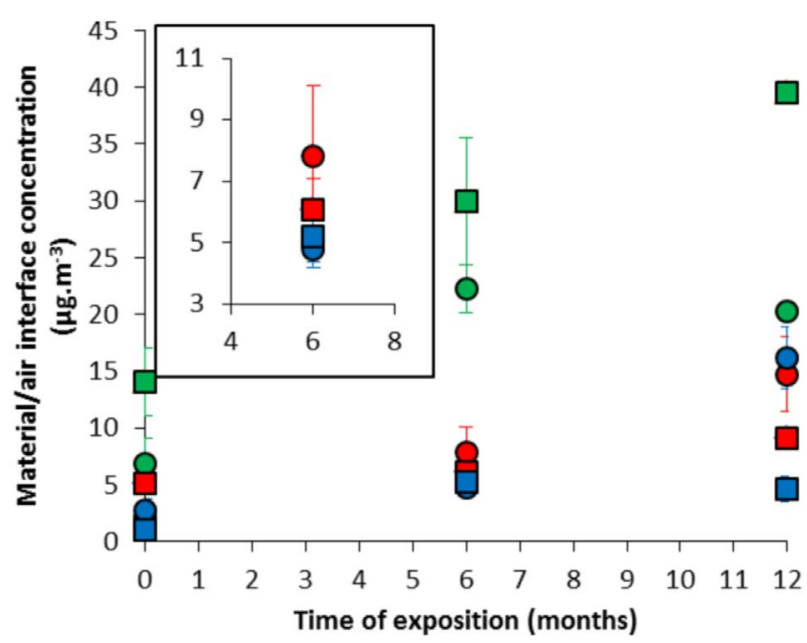

Fig. 8. Formaldehyde (spheres) and acetaldehyde (squares) surface concentrations over the weathering (blue: PP, red: PP10, green: PP30) (PDMS/DVB SPME fiber impregnated with PFBHA - sampling at $23{ }^{\circ} \mathrm{C}$ ). (For interpretation of the references to colour in this figure legend, the reader is referred to the Web version of this article.)

Table 4

Formaldehyde, acetaldehyde and TVOCs levels (ST: sampling temperature).

\begin{tabular}{lllllllll}
\hline & ST $\left({ }^{\circ} \mathrm{C}\right)$ & \multicolumn{2}{l}{ Surface concentration $\left(\mu \mathrm{g} . \mathrm{m}^{-3}\right)$} \\
\cline { 3 - 8 } & & & \multicolumn{5}{l}{ Before weathering } & \multicolumn{4}{l}{ After weathering } \\
\cline { 3 - 8 } & & PP & PP10 & PP30 & PP & PP10 & PP30 \\
\hline Formaldehyde & $\mathbf{2 3}$ & 2.8 & 2.24 & 6.9 & 16.2 & 14.7 & 20.3 \\
Acetaldehyde & $\mathbf{2 3}$ & - & 5.1 & 14.1 & 4.6 & 9.1 & 39.5 \\
TVOCs & $\mathbf{2 3}$ & - & - & - & 19 & 112 & 124 \\
& $\mathbf{8 0}$ & 6342 & 8322 & 9267 & 7676 & 35284 & 30849 \\
\hline
\end{tabular}

Table 5

Guideline and recommended standard limit values.

\begin{tabular}{llll}
\hline & \multicolumn{2}{l}{ VIAQ limit values $\left(\mu \mathrm{g} \cdot \mathrm{m}^{-3}\right)$} \\
\cline { 2 - 4 } & JAMA (Japan) & $\mathrm{GB} / \mathrm{T} \mathrm{27630}$ (China) & No 2007-539 (Korea) \\
\hline Formaldehyde & 100 & 100 & 250 \\
Acetaldehyde & 48 & 50 & - \\
TVOCs & - & - & - \\
\hline
\end{tabular}


$Q_{i j}=h_{i j} \frac{A_{j}}{V\left(C_{s i j}-C_{\mathrm{i}}\right)}$

with $h_{i j}$ the convective mass transfer coefficient of pollutant $i$ through the boundary layer over the material $j\left(\mathrm{~m}_{\mathrm{s}} \mathrm{s}^{-1}\right), \mathrm{A}_{\mathrm{j}}$ the surface area of the material $\mathrm{j}\left(\mathrm{m}^{2}\right), \mathrm{V}$ the volume of the studied indoor environment $\left(\mathrm{m}^{3}\right), \mathrm{C}_{\mathrm{sij}}$ the concentration of the pollutant $\mathrm{i}$ at the material surface and $C_{i}$ the average indoor air concentration of the pollutant $i\left(\mu \mathrm{g} \cdot \mathrm{m}^{-3}\right)$.

Table 4 shows that surface concentrations of aldehydes slightly increased over the weathering but they are always lower than their respective indoor concentration limits. Hence, the materials studied here are considered as very low emissive regarding these compounds and they would comply with the current VIAQ regulations.

Currently, no VIAQ standard or guideline has been found preconizing TVOCs limit concentration. However, as reported in the introductory part, TVOCs indoor concentration is an indicator of health effects. Relationship between TVOCs levels found in indoor air and discomfort felt by individuals has been investigated through epidemiological studies [58]. Four exposure ranges were proposed that are a comfort $\left(<20 \mu \mathrm{g} \mathrm{m}^{-3}\right)$, a multifactorial exposure $\left(20-300 \mu \mathrm{g} \mathrm{m}^{-3}\right)$, a discomfort (300-25000 $\left.\mu \mathrm{g} \mathrm{m}^{-3}\right)$, and a toxic $\left(>25000 \mu \mathrm{g} \mathrm{m}^{-3}\right)$ ranges. Weathered PP10 and PP30 can imply possible irritation and discomfort if other exposures interact according to this dose-response model. However, all materials may potentially cause more severe effects when they are heated at $80^{\circ} \mathrm{C}$. This assumption should be moderated by the fact that biocomposites are generally implemented with other materials (for example, door panels). Thus, linings and coatings can act as barrier and reduce biocomposite emission in indoor air, as observed for other material assemblies $[59,60]$.

\section{Conclusion}

An original methodology for the analysis of emitted VOCs by materials was applied to the study of one-year weathering of biocomposites in comparison with neat polymer (PP). The weathering had a higher impact on the evolution of VOCs types and emitted concentrations of biocomposites than of neat PP. At non-weathered state, the greater the hemp fiber loading was, the higher the emitted VOCs amount was. Moreover, the VOCs emission drastically increased for the highest loading (PP30) after 12 months of weathering. Oxygenated products mostly contributed to the weathered biocomposites emission concentration, demonstrating an oxidative degradation due to UV radiation and high temperatures. A major part of these compounds was shown to originate from hemp fibers but some of them were only detected in biocomposites emissions (non-identified in the hemp fibers individual analysis), assuming possible prodegrading effect. VOCs emissions characterization can be thus a useful way for understanding degradation mechanisms explaining the formation of products issued from the polymer matrix and from the carbohydrates and lignin decomposition.

Regarding the application of these composites in car cabins, all VOCs toxicity was checked. A potential impact on VIAQ was noted because of the release of some products issued from both PP and vegetal fibers. Even if their concentrations satisfy with current VIAQ regulation, this emphasizes a drawback of these fibers reinforced polymers regarding their use in indoor environments because of the higher concentration of hazardous VOCs emitted by biocomposites than virgin PP. The TVOCs level, which considerably increased with weathering time, the temperature and the hemp fiber rate, indicated that health effects by exposition to heated aged biocomposites could become of greater concern. Nevertheless, biocomposites in vehicles are generally implemented in materials assemblies and possible barrier effects could reduce the impact on VIAQ.

\section{Acknowledgements}

This research did not receive any specific grant from funding agencies in the public, commercial, or not-for-profit sectors.

\section{References}

[1] Nova Institut, Feature wind energy, n99, JEC Compos. Mag (2015) 18-19.

[2] D. Müller, D. Klingelhöfer, S. Uibel, D. a Groneberg, Car indoor air pollution analysis of potential sources, J. Occup. Med. Toxicol. 6 (2011) 33, http://dx.doi. org/10.1186/1745-6673-6-33.

[3] X. Chen, G. Zhang, H. Chen, Controlling strategies and technologies of volatile organic compounds pollution in interior air of cars, Proc. 2010 Int. Conf. Digit. Manuf. Autom. ICDMA 2010 (1) (2010) 450-453, http://dx.doi.org/10.1109/ ICDMA.2010.375.

[4] MCS-Aware, Sick Car Syndrome, (2015) http://www.mcs-aware.org/generalarticles/189-sick-car-syndrome, Accessed date: 5 January 2017.

[5] J.S. Félix, C. Domeño, C. Nerín, Characterization of wood plastic composites made from landfill-derived plastic and sawdust: volatile compounds and olfactometric analysis, Waste Manag. 33 (2013) 645-655, http://dx.doi.org/10.1016/j.wasman. 2012.11.005.

[6] K. Sakakibara, K. Kaitani, C. Hamada, S. Sato, M. Matsuo, Analysis of odor in car cabin, JSAE Rev. 20 (1999) 237-241, http://dx.doi.org/10.1016/S0389-4304(98) 00073-3.

[7] Underwriters Laboratories UL LLC, Vehicle Interior Air Quality: Addressing Chemical Exposure in Automobiles, (2015).

[8] H. Kim, B. Lee, S. Choi, Sustainable Biocomposites for Automotive Interior Parts, in 18TH Int. Conf. Compos. Mater, (2011), pp. 1-4.

[9] Korean Automobile Testing \& Research Institute, Proposal for Vehicle Indoor Air Quality (VIAQ), GRPE-69-28, (2014), pp. 5-6.

[10] Ministry of Environmental Protection, GB/T 27630-2011 Chinese National Standard: Guideline for Air Quality Assesment of Passenger Car, (2011).

[11] JAMA, Announces Voluntary Guidelines for Reducing Vehicle Cabin VOC Concentration Levels, (2005) http://www.jama-english.jp/.

[12] European Automobile Manufacturers Association. (n.d.). http://www.acea.be/.

[13] ISO 12219-1: Whole Vehicle Test Chamber — Specification and Method for the Determination of Volatile Organic Compounds in Cabin Interiors, (2012).

[14] ISO 12219-2: Screening Method for the Determination of the Emissions of Volatile Organic Compounds from Vehicle Interior Parts and Materials - Bag Method, (2012).

[15] ISO 12219-3: Screening Method for the Determination of the Emissions of Volatile Organic Compounds from Vehicle Interior Parts and Materials - Micro-scale Chamber Method, (2012).

[16] K.-W. Kim, B.-H. Lee, S. Kim, H.-J. Kim, J.-H. Yun, S.-E. Yoo, J.R. Sohn, Reduction of VOC emission from natural flours filled biodegradable bio-composites for automobile interior, J. Hazard Mater. 187 (2011) 37-43, http://dx.doi.org/10.1016/j. jhazmat.2010.07.075.

[17] B. Xu, Y. Wu, Y. Gong, S. Wu, X. Wu, S. Zhu, T. Liu, Investigation of volatile organic compounds exposure inside vehicle cabins in China, Atmos. Pollut. Res. 7 (2015) 215-220, http://dx.doi.org/10.1016/j.apr.2015.09.005.

[18] Y.C. Chien, Variations in amounts and potential sources of volatile organic chemicals in new cars, Sci. Total Environ. 382 (2007) 228-239, http://dx.doi.org/10. 1016/j.scitotenv.2007.04.022.

[19] T. Yoshida, I. Matsunaga, A case study on identification of airborne organic compounds and time courses of their concentrations in the cabin of a new car for private use, Environ. Int. 32 (2006) 58-79, http://dx.doi.org/10.1016/j.envint.2005.04. 009.

[20] M.J. Fedoruk, B.D. Kerger, Measurement of volatile organic compounds inside automobiles, J. Expo. Anal. Environ. Epidemiol. 13 (2003) 31-41, http://dx.doi.org/ 10.1038/sj.jea.7500250.

[21] S. Kim, J.-A. Kim, H.-J. Kim, S. Do Kim, Determination of formaldehyde and TVOC emission factor from wood-based composites by small chamber method, Polym. Test. 25 (2006) 605-614, http://dx.doi.org/10.1016/j.polymertesting.2006.04. 008.

[22] S. Overton, J. Manura, Identification of volatile organic compounds in a new automobile, Sci. Instrum. Serv. Inc (1999) 1-6.

[23] Y. Peng, R. Liu, J. Cao, Characterization of surface chemistry and crystallization behaviour of polypropylene composites reinforced with wood flour, cellulose, and lignin during accelerated weathering, Appl. Surf. Sci. (2015), http://dx.doi.org/10. 1016/j.apsusc.2015.01.147.

[24] J.S. Fabiyi, A.G. McDonald, M.P. Wolcott, P.R. Griffiths, Wood plastic composites weathering: visual appearance and chemical changes, Polym. Degrad. Stabil. 93 (2008) 1405-1414, http://dx.doi.org/10.1016/j.polymdegradstab.2008.05.024.

[25] O. Gil-Castell, J.D. Badia, T. Kittikorn, E. Strömberg, A. Martínez-Felipe, M. Ek, S. Karlsson, A. Ribes-Greus, Hydrothermal ageing of polylactide/sisal biocomposites. studies of water absorption behaviour and physico-chemical performance, Polym. Degrad. Stabil. 108 (2014) 212-222, http://dx.doi.org/10.1016/j. polymdegradstab.2014.06.010.

[26] M.Z. Ahmad Thirmizir, Z.A. Mohd Ishak, R. Mat Taib, S. Rahim, S. Mohamad Jani, Natural weathering of kenaf bast fibre-filled poly(butylene succinate) composites: effect of fibre loading and compatibiliser addition, J. Polym. Environ. 19 (2010) 
263-273, http://dx.doi.org/10.1007/s10924-010-0272-2.

[27] D. Chen, J. Li, J. Ren, Influence of fiber surface-treatment on interfacial property of poly(l-lactic acid)/ramie fabric biocomposites under UV-irradiation hydrothermal aging, Mater. Chem. Phys. 126 (2011) 524-531, http://dx.doi.org/10.1016/j. matchemphys.2011.01.035.

[28] L. Soccalingame, D. Perrin, J.-C. Bénézet, S. Mani, F. Coiffier, E. Richaud, A. Bergeret, Reprocessing of artificial UV-weathered wood flour reinforced polypropylene composites, Polym. Degrad. Stabil. 120 (2015) 313-327, http://dx.doi org/10.1016/j.polymdegradstab.2015.07.013.

[29] L. Soccalingame, D. Perrin, J.-C. Bénézet, A. Bergeret, Reprocessing of UV-weathered wood flour reinforced polypropylene composites: study of a natural outdoor exposure, Polym. Degrad. Stabil. 133 (2016) 389-398, http://dx.doi.org/10.1016/ j.polymdegradstab.2016.09.011.

[30] C. Badji, L. Soccalingame, H. Garay, A. Bergeret, J.-C. Bénézet, Influence of weathering on visual and surface aspect of wood plastic composites: correlation approach with mechanical properties and microstructure, Polym. Degrad. Stabil. 137 (2017) 162-172, http://dx.doi.org/10.1016/j.polymdegradstab.2017.01.010.

[31] A. Espert, L.A. de las Heras, S. Karlsson, Emission of possible odourous low molecular weight compounds in recycled biofibre/polypropylene composites monitored by head-space SPME-GC-MS, Polym. Degrad. Stabil. 90 (2005) 555-562, http://dx. doi.org/10.1016/j.polymdegradstab.2005.03.009.

[32] H.-S. Kim, B.-H. Lee, H.-J. Kim, H.-S. Yang, Mechanical-thermal properties and VOC emissions of natural-flour-filled biodegradable polymer hybrid bio-composites, J. Polym. Environ. 19 (2011) 628-636, http://dx.doi.org/10.1007/s10924-0110313-5.

[33] ISO 16000-16009: Indoor Air - Part 9: Determination of the Emission of Volatile Organic Compounds from Building Products and Furnishing - Emission Test Chamber Method, (2006).

[34] ISO 16000-16006: Indoor Air - Part 6: Determination of Volatile Organic Compounds in Indoor and Test Chamber Air by Active Sampling on Tenax TA Sorbent, Thermal Desorption and Gas Chromatography Using MS or MS-FID, (2011).

[35] Ó. Ezquerro, B. Pons, M.T. Tena, Development of a headspace solid-phase microextraction-gas chromatography-mass spectrometry method for the identification of odour-causing volatile compounds in packaging materials, J. Chromatogr. A 963 (2002) 381-392, http://dx.doi.org/10.1016/S0021-9673(02)00211-X.

[36] J. Salafranca, I. Clemente, F. Isella, C. Nerín, O. Bosetti, Influence of oxygen and long term storage on the profile of volatile compounds released from polymeric multilayer food contact materials sterilized by gamma irradiation, Anal. Chim. Acta 878 (2015) 118-130, http://dx.doi.org/10.1016/j.aca.2015.03.055.

[37] P. Kusch, G. Knupp, Headspace-SPME-GC-MS identification of volatile organic compounds released from expanded polystyrene, 12 (2004) 83-87.

[38] D. Bourdin, P. Mocho, V. Desauziers, H. Plaisance, Formaldehyde emission behavior of building materials: on-site measurements and modeling approach to predict indoor air pollution, J. Hazard Mater. 280 (2014) 164-173, http://dx.doi.org/10. 1016/j.jhazmat.2014.07.065.

[39] V. Desauziers, D. Bourdin, P. Mocho, H. Plaisance, Innovative tools and modeling methodology for impact prediction and assessment of the contribution of materials on indoor air quality, Herit. Sci. 3 (2015) 1, http://dx.doi.org/10.1186/s40494015-0057-y.

[40] D. Bourdin, V. Desauziers, Development of SPME on-fiber derivatization for the sampling of formaldehyde and other carbonyl compounds in indoor air, Anal. Bioanal. Chem. 406 (2014) 317-328, http://dx.doi.org/10.1007/s00216-0137460-6.

[41] Chemical Risk Prevention Unit, CNRS, European Harmonised Classification and Labelling of Carcinogenic, Mutagenic and Toxic for Reproduction (CMR) Substances According to the Criteria of the CLP Regulation, (2015).

[42] J.A. Koziel, J. Noah, J. Pawliszyn, Field sampling and determination of formaldehyde in indoor air with solid-phase microextraction and on-fiber derivatization, Environ. Sci. Technol. 35 (2001) 1481-1486, http://dx.doi.org/10.1021/ es001653i.
[43] J. Nicolle, V. Desauziers, P. Mocho, Solid phase microextraction sampling for a rapid and simple on-site evaluation of volatile organic compounds emitted from building materials, J. Chromatogr. A 1208 (2008) 10-15, http://dx.doi.org/10. 1016/j.chroma.2008.08.061.

[44] V. Desauziers, Traceability of pollutant measurements for ambient air monitoring, Trends Anal. Chem. 23 (2004) 252-260, http://dx.doi.org/10.1016/S01659936(04)00310-3.

[45] S. Wang, X. Guo, T. Liang, Y. Zhou, Z. Luo, Mechanism research on cellulose pyrolysis by Py-GC/MS and subsequent density functional theory studies, Bioresour. Technol. 104 (2012) 722-728, http://dx.doi.org/10.1016/j.biortech.2011.10.078.

[46] M. Carrier, A. Loppinet-Serani, C. Absalon, C. Aymonier, M. Mench, Degradation pathways of holocellulose, lignin and alpha-cellulose from Pteris vittata fronds in sub- and super critical conditions, Biomass Bioenergy 43 (2012) 65-71, http://dx. doi.org/10.1016/j.biombioe.2012.03.035.

[47] Y. Peng, S. Wu, Fast pyrolysis characteristics of sugarcane bagasse hemicellulose, Cellul. Chem. Technol. 45 (2011) 605-612.

[48] Y. Peng, R. Liu, J. Cao, Y. Chen, Effects of UV weathering on surface properties of polypropylene composites reinforced with wood flour, lignin, and cellulose, Appl. Surf. Sci. 317 (2014) 385-392, http://dx.doi.org/10.1016/j.apsusc.2014.08.140.

[49] G. Bonifazi, L. Calienno, G. Capobianco, A. Lo, C. Pelosi, R. Picchio, S. Serranti, Modeling color and chemical changes on normal and red heart beech wood by reflectance spectrophotometry, Fourier transform infrared spectroscopy and hyperspectral imaging, Polym. Degrad. Stabil. 113 (2015) 10-21, http://dx.doi.org/ 10.1016/j.polymdegradstab.2015.01.001.

[50] R. Bernstein, S.M. Thornberg, A.N. Irwin, J.M. Hochrein, D.K. Derzon, S.B. Klamo, R.L. Clough, Radiation-oxidation mechanisms: volatile organic degradation products from polypropylene having selective C-13 labeling studied by GC/MS, Polym. Degrad. Stabil. 93 (2008) 854-870, http://dx.doi.org/10.1016/j.polymdegradstab. 2008.01.020.

[51] O. Faruk, A.K. Bledzki, H.-P. Fink, M. Sain, Biocomposites reinforced with natural fibers: 2000-2010, Prog. Polym. Sci. 37 (2012) 1552-1596, http://dx.doi.org/10. 1016/j.progpolymsci.2012.04.003.

[52] Z.L. Yan, H. Wang, K.T. Lau, S. Pather, J.C. Zhang, G. Lin, Y. Ding, Reinforcement of polypropylene with hemp fibres, Compos. B Eng. 46 (2013) 221-226, http://dx.doi. org/10.1016/j.compositesb.2012.09.027.

[53] L. Sisti, G. Totaro, M. Vannini, P. Fabbri, S. Kalia, A. Zatta, A. Celli, Evaluation of the retting process as a pre-treatment of vegetable fibers for the preparation of highperformance polymer biocomposites, Ind. Crop. Prod. 81 (2016) 56-65, http://dx. doi.org/10.1016/j.indcrop.2015.11.045.

[54] P. Md Tahir, A.B. Ahmed, S.O.A. SaifulAzry, Z. Ahmed, Retting process of some bast plant fibres and its effect on fibre quality: a review, BioResources 6 (2011) 5260-5281, http://dx.doi.org/10.15376/biores.6.4.5260-5281.

[55] O.F. Unit, C. Scouring, Influence of wet processing on physico-chemical properties of okra bast fibre, 29 (2016) 412-414.

[56] R. Wittkowski, J. Ruther, H. Drinda, F. Rafiei-Taghanaki, Formation of smoke flavor compounds by thermal lignin degradation, ACS Symp. Ser 490 (1992) 232-243.

[57] M. Baharoğlu, G. Nemli, B. Sarı, S. Bardak, N. Ayrılmış, The influence of moisture content of raw material on the physical and mechanical properties, surface roughness, wettability, and formaldehyde emission of particleboard composite, Compos. B Eng. 43 (2012) 2448-2451, http://dx.doi.org/10.1016/j.compositesb. 2011.10.020.

[58] L. Molhave, Volatile organic compounds, indoor air quality and health, Indoor Air 1 (1991) 357-376, http://dx.doi.org/10.1111/j.1600-0668.1991.00001.x.

[59] K.W. Kim, S. Kim, H.J. Kim, J.C. Park, Formaldehyde and TVOC emission behaviors according to finishing treatment with surface materials using $20 \mathrm{~L}$ chamber and FLEC, J. Hazard Mater. 177 (2010) 90-94, http://dx.doi.org/10.1016/j.jhazmat. 2009.09.060.

[60] G. Nemli, G. Colakoğlu, The influence of lamination technique on the properties of particleboard, Build. Environ. 40 (2005) 83-87, http://dx.doi.org/10.1016/j. buildenv.2004.05.007. 